\title{
CAPTAÇÕES FOTOGRÁFICAS EXPERIMENTAIS COM PROJEÇÕES
}

\author{
Elisangela Lobo Schirigatti \\ Universidade Tecnológica Federal do Paraná - UTFPR \\ elisangelal@utfpr.edu.br \\ Luis Fernando Fonseca Kasprzak \\ Pontifícia Universidade Católica do Paraná - PUCPR \\ luis.kasprzak@pucpr.br
}

Resumo: A captação fotográfica utilizando projeção é uma técnica considerada de rica expressão artística e, apesar de ser antiga, continua despertando a atenção de muitos fotógrafos. Com base no repertório artístico abordado na revisão de literatura e considerando a descrição da técnica visando sua melhor reprodutibilidade, os alunos da disciplina de Fotografia, do curso de Tecnologia em Design Gráfico de uma instituição do ensino superior em Curitiba, realizaram diversas captações com vários temas. Os resultados mostraram a importância entre a qualidade da luz do projetor com a qualidade da imagem projetada; das questões de nitidez com o uso do tripé e a pose estática do modelo; das cores da vestimenta da modelo com as cores da imagem projetada; do enquadramento obtido com a posição do projetor; e da volumetria do objeto fotografado com a atenuação das sombras. A proposição de projetos de extensão que incluem a experimentação de novas técnicas são importantes para a absorção do conhecimento docente e influenciam na decisão de implementação de novos desafios no meio acadêmico. Nesse caso, o contato dos docentes com a técnica de captação fotográfica utilizando projeções que ocorreu a partir das atividades desenvolvidas no atelier de fotografia foi um mecanismo propulsor que contribuiu para a adoção da técnica nas aulas de fotografia.

Palavras-chave: Projeção, sobreposição, experimento fotográfico

\begin{abstract}
The picture-taking using projection is a technique considered rich artistic expression and, although old, still attracting attention of many photographers. Based on the artistic repertoire covered in the literature review and considering the technical description aiming at their better reproducibility, the students of the Photography discipline, of Course Technology in Graphic Design of an institution of higher education in Curitiba, made several captures with various themes. The results showed the importance of the quality of the projector light with the quality of the projected image; the sharpness issues using the tripod and the static pose of the model; the model of clothing colors with the colors of the projected
\end{abstract}


image; the frame obtained with the projector's position; and volumes of the object photographed with the attenuation of the shadows. The proposal of extension projects which include the testing of new techniques are important for the absorption of teaching knowledge and influence in the implementation of decision of new challenges in academia. In this case, the contact of teachers with the picture-taking technique using projections that occurred from activities in the photo studio was a driving mechanism which contributed to the adoption of the technique in photography classes.

Keywords: Projection, overlap, photographic experiment

\section{INTRODUÇÃO}

A captação fotográfica utilizando projeção é uma técnica considerada de rica expressão artística. Para Goldstein (2014), a técnica de unir fotografia com projeção não é nova e surgiu na década de 1960 com as captações preto e branco que com a evolução dos recursos tecnológicos evoluíram para o colorido e foram incrementadas com outros efeitos de luz. Para o artista, as projeções na fotografia encantam pois abrem uma infinidade de múltiplas criações e um universo de novas possibilidades.

Com o tempo a técnica se tornou popular e ainda continua seduzindo e inspirando a criatividade de muitos fotógrafos e artistas, tais como: Massarella (2010), Crawley (2012), Clang (2012), Ayer (2014), Eshchar (2014), Mueller (2014) e FitzGerald (2014). Apesar da técnica ser muito utilizada por artistas e profissionais nos dias atuais como recurso criativo para obras autorais e para o meio publicitário, nenhum estudo foi encontrado na área de fotografia acadêmica. Mesmo sendo assim, a técnica é considerada de fácil reprodutibilidade e muito interessante como atividade criativa.

No campo didático, a implementação e realização de exercícios práticos durante o ensino de fotografia contribuem na consolidação dos conceitos teóricos e podem servir como um meio gerador de projetos e propulsor de experimentações. Por essas razões, essa prática pode ser adotada em ambiente acadêmico e incluida na ementa das disciplinas de fotografia, em especial nos cursos de design.

Portanto, dentro do contexto abordado, o presente trabalho visa descrever e analisar os resultados obtidos com a técnica de captação fotográfica com sobreposições fotográficas utilizando o projetor.

\section{DESENVOLVIMENTO}

\subsection{0 uso do projetor nas captações fotográficas artísticas}

Segundo o dicionário digital, o termo projeção significa utilizar um equipamento e luz para causar uma imagem de um objeto ou original para ser visto numa tela, sendo que usualmente a imagem é maior que a original (IDIGITALPHOTO, 2014).

Uma referência dos anos 60 foi o fotógrafo de modelos John French que projetou padrões florais no corpo de modelos ao invés de suas roupas (GOLDSTEIN, 2014). Outro trabalho de destaque foi o videoclipe da música "I drove all night" do álbum solo "A Night to Remember" de Cyndi Lauper que foi lançado em 1989. O vídeo da música foi dirigido por Scott Kalvert e consiste em mostrar uma película de filme projetado nas costas do corpo nu da cantora (LAUPER, 1989). 
Outro exemplo é o da fotógrafa Ashley Sophia Massarella que em 2010 realizou 06 captações fotográficas de projeções textuais e luminosas aleatórias em corpos femininos seminus. Mostrando o rosto e enquadrando as costas, tronco superior frontal e a lateral do corpo.

Uma coletânea considerável aplicando a técnica é aquela concentrada no livro "Body Projection" de Crawley (2012). O projeto de captações durou 20 anos e utilizou 20 modelos. Dentro de um contexto sensual, o fotógrafo registrou as projeções de marcas, texturas e figuras geométricas em corpos nus femininos.

Já o fotógrafo John Clang (2012), sensível a fragmentação familiar advinda dos tempos modernos, promoveu uma união de integrantes que moram longe um dos outros por meio da tecnologia. O retrato de família é uma tradição em Cingapura e o afastamento por motivo de trabalho ou estudo dificulta sua concretização. A técnica utilizou a projeção em tamanho natural de alguns parentes distantes ao lado de outros membros da família para uma segunda captação. O resultado desses retratos modernos que unem famílias virtualmente foi intitulado "Being together" e foi exposto em 2013 no Museu Nacional de Cingapura e, em 2014, no Centro de Cultura Contemporânea Strozzina em Florence na Itália com o nome de "Problemas Familiares".

Por sua vez, a série "Time Travel" do fotógrafo Davis Ayer (2014) também se utilizou de projeções fotográficas de elementos arquitetônicos e texturas em corpos de mulheres seminuas posicionadas em frente a um fundo preto. As experimentações tiveram o objetivo de criar novos efeitos, composições únicas e seu trabalho resultou em uma mistura de elementos na projeção, incluindo tatuagens.

Mais recentemente, o artista Tom Eshchar (2015) publicou a série "No face" composta de 65 fotografias que mesclam a projeção de imagens digitais, compostas por desenhos coloridos, fotografia de pessoas famosas, seres alados, estampas geométricas ou obras de arte. Em seu trabalho, figura 1, é comum encontrar o corpo inteiro de homens seminus e mulheres nuas, que em geral apresentam, a face ocultada pelos cabelos (DYPHOTOGRAPHY, 2012).

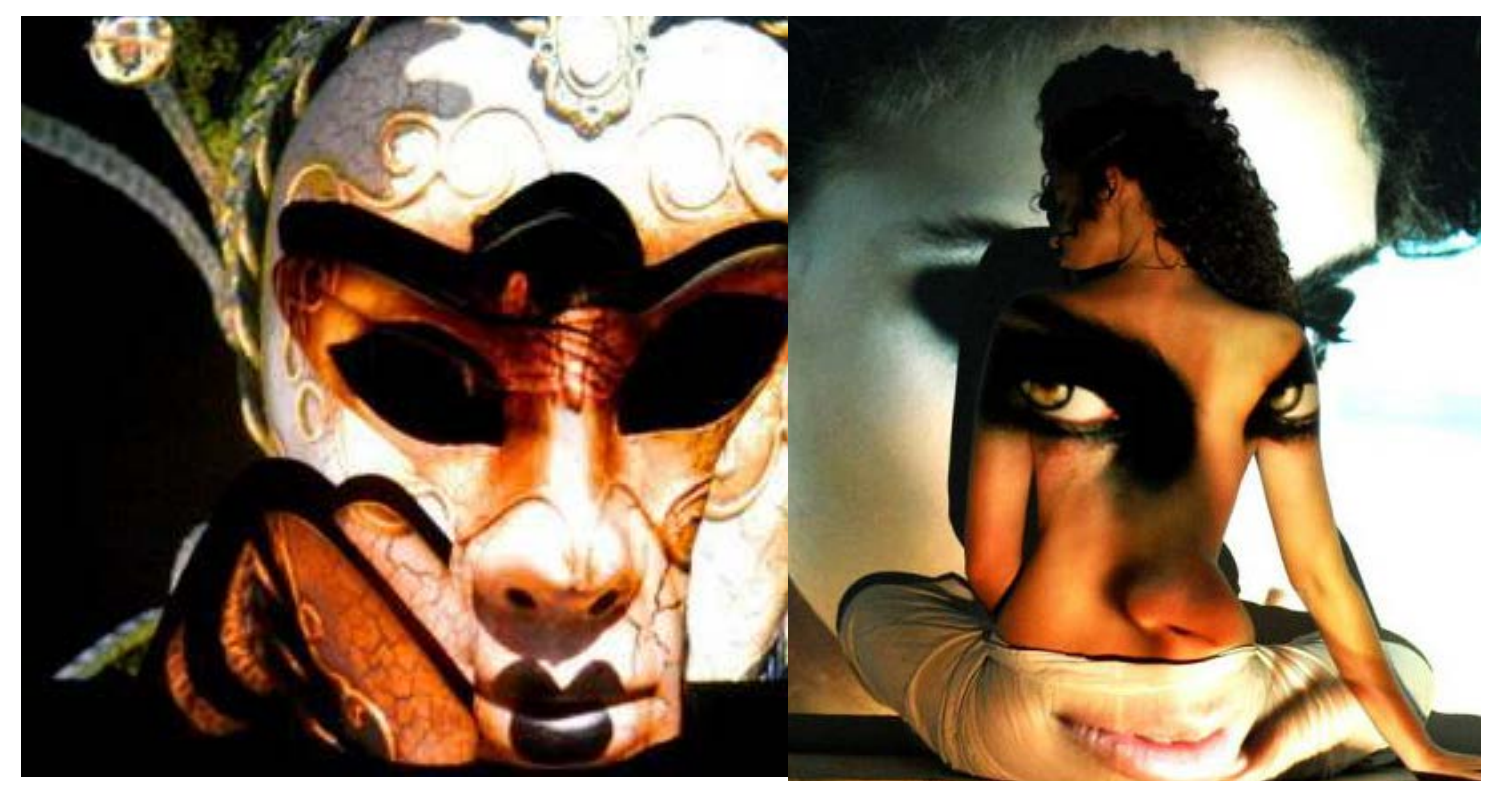

Figura 1 - Fotografias que compõem o projeto No Face Fonte: Eshchar (2015) 
Ainda em 2014, Eva Mueller (2014) também construiu a série "Projections" com 42 fotografias e utiliza textura, elementos da natureza e formas geométricas. No entanto, ao contrário de Eshchar, a fotógrafa prefere exibi-las em um fundo branco liso, obtido provavelmente na pós-produção, proporcionando um contraste maior e uma atmosfera mais clean ao projeto. Contudo, as fotografias com projeções de marcas consagradas, possuem uma característica de enquadramento mais fechado, 0 fundo azul escuro degrade e realce para os símbolos.

Na mesma linha e tempo, Hanna FitzGerald (2014) optou em projetar padrões florais em corpos femininos nus. Preferindo porém, ora pelo fundo preto e ora por um fundo branco. Nesse último caso, os elementos padronais se estendem da modelo até as bordas. Assim, as fotos brancas aparecem totalmente preenchidas por contrastes intrigantes obtidos com a dureza do branco e do preto.

Seguindo uma outra linha, Mawad e Van Schoor (2014) realizaram projeções na floresta com objetivo de transmitir uma sensação de vida aos seus elementos, entre eles as árvores, folhas, musgos, besouros e outros animais.

Por fim, é importante ressaltar que, apesar de se tratar da mesma técnica, os artistas analisados buscaram aplicá-la de forma a transcrever climas diferentes em suas captações, criando uma atmosfera de excitação e versatilidade única, que os representam e os diferem no universo artístico.

\subsection{Princípios técnicos da captação com projetor}

Apesar de Crawley ter seu livro publicado em 2012, o projeto "Body Projection" teve início em 1992. Naquela época, as projeções de transparências eram realizadas com filme slide $35 \mathrm{~mm}$ e as captações eram realizadas com filme slide de tungstênio Ektakhrome 64 T ou 120T.

Atualmente as captações são feitas com câmeras digitais e as imagens projetadas com mais performance, incluindo qualidade e rendimento com 2700 ANSI Lumens, com poder de projeção entre 23 a 350" (polegadas), ou seja, 58,48 a 889,0 $\mathrm{cm}$. Segundo Crawley (2012), a única luz utilizada é aquela advinda do projetor e por isso a modelo deve manter-se estática por um longo tempo devido a necessidade da longa exposição, o que também explica a utilidade de um tripé.

Tecnicamente, a intensidade da luz do projetor reflete diretamente na qualidade da imagem projetada e, portanto, nos resultados obtidos. Por isso, é recomendável verificar a luz nos testes que antecedem a presença da modelo. Os projetores apresentam uma ampla variedade de níveis de brilho, que é medido em Lumens. A norma Color Light Output (2015), também denominada de Color Brightness, foi publicada em maio de 2012 e padroniza essa medida. Assim, quanto maior a quantidade de lumens um projetor tiver, mais viva e brilhante será a imagem projetada (EPSON, 2015a).

Além do brilho na cor branca, é importante a capacidade do brilho em cores do aparelho. De acordo com a International Committee for Display Metrology (2012), essa medida dará uma informação muito mais precisa de como será a imagem projetada. Para algumas marcas, o brilho em cores pode chegar a ser um terço do valor do brilho em branco, gerando imagens mais apagadas e com cores menos naturais.

Para melhores resultados, o aparelho de projeção deve ser operado numa área onde a luz possa ser controlada. Quanto mais escuro for o ambiente, mais brilhante e perfeita será a imagem. 
Crawley (2012) descreve que o foco deve estar no rosto ou no corpo da modelo. A transparências coloridas suaves são mais interessantes para os fundos escuros. Assim como as composições abstratas de repetição que possuem contorno bem definido, tipo mandala, são interessantes para serem projetadas na pele ou em tecido branco.

Outro quesito a ser considerado é a posição do aparelho de projeção, esse deve ficar com a área posicionada sobre a área do desenho que se deseja projetar. A posição do projetor e o tamanho da imagem irão depender da configuração da sala. Portanto, é preciso levar em conta a distância de projeção e as funções do projetor para decidir onde colocar o equipamento para uma maximização da iluminação.

Sendo que, a regra é clara, para mudar o tamanho da imagem, recomenda-se aumentar a distância entre o projetor e a superfície que recebe a projeção para se obter grandes ampliações.

Visando auxiliar nessa tarefa, alguns produtores disponibilizam calculadoras interativas em seus websites que permitem estimar a melhor distância e posicionamento do produto (Figura 2).

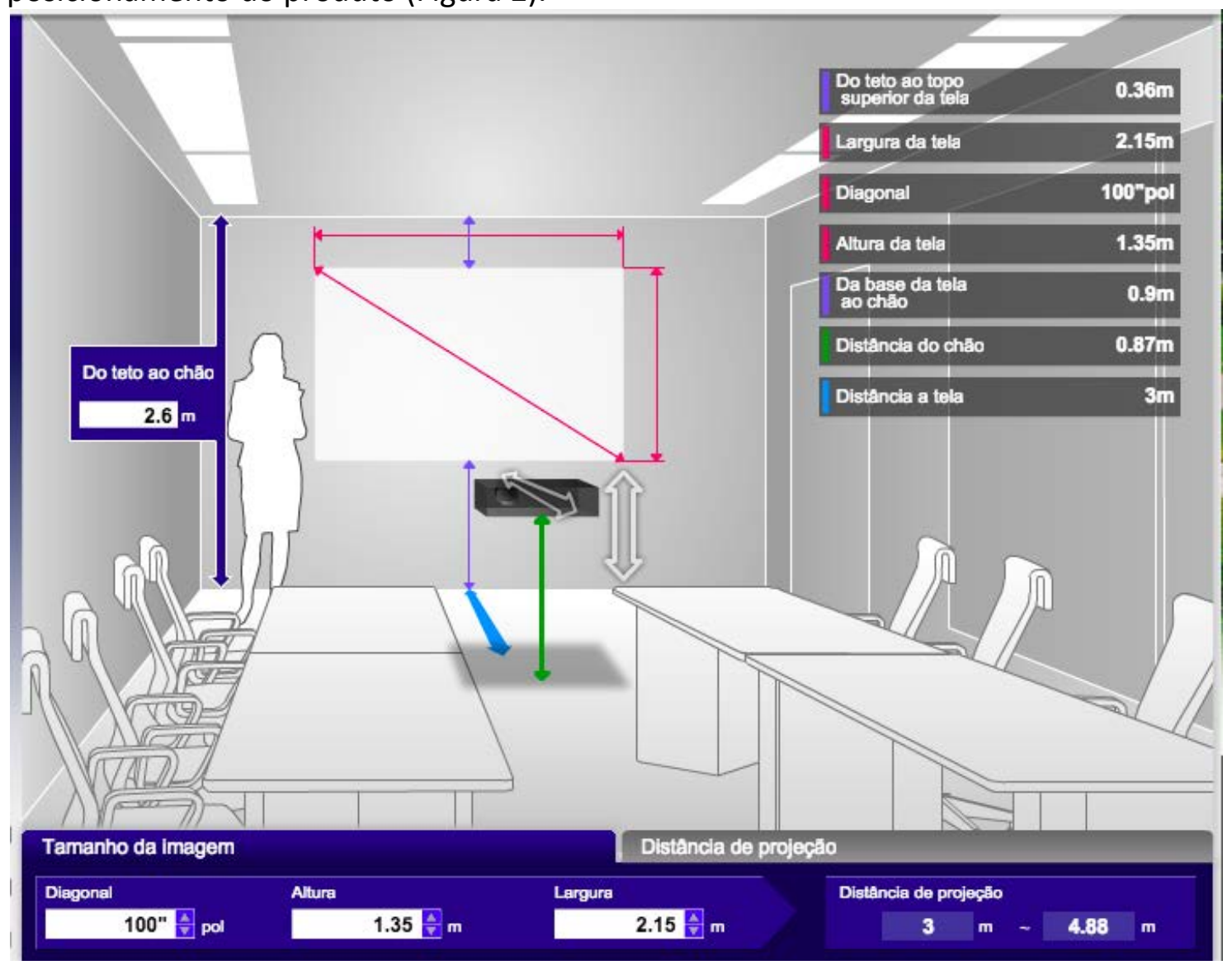

Figura 2 - Calculadora para estimar a distância de projeção.

Fonte: EPSON (2015b)

\subsection{Aplicação da técnica do projetor no meio acadêmico}

A técnica de captação fotográfica utilizando projeções foi abordada inicialmente em um atelier de fotografia realizado no final de 2014. $O$ atelier foi um projeto de extensão proposto pelos professores de fotografia do departamento de Design de uma universidade de Curitiba, no estado do Paraná. Participararam dessa 
experimentação docentes e discentes do curso de Bacharelado em Design e Tecnologia em Design Gráfico da instituição em questão.

Depois disso, a prática da projeção foi adotada como uma atividade dentro da disciplina de fotografia dos cursos de Tecnologia em Design Gráfico. Para tal, foram utilizadas 02 horas/aula para a parte teórica e 05 horas/aula para as aulas práticas, totalizando uma carga horária de 07 horas/aula destinadas tanto para a turma da manhã quanto para a turma da noite. A aplicação da técnica ocorreu durante o primeiro semestre de 2015 , sendo que a atividade foi repetida no segundo semestre de 2015 e no primeiro de 2016 na mesma disciplina, contabilizando 06 turmas.

A princípio, a técnica foi explanada em aula teórica na semana que antecedeu as captações. Nesse encontro, também foram mostrados exemplos das obras criadas pelos principais artistas e profissionais da área, seguido pelo timeline histórico da técnica. Na sequência, foi solicitado à cada participante escolher para o próximo encontro um conjunto de imagens disponíveis de forma gratuíta na internet e definir uma pose de interação para cada uma delas.

Os temas podiam ser inspirados na representação de figuras com padronagens, tanto coloridas como preto e branco. Nesse caso, as imagens podiam ser escolhidas primando o fator fechamento, que valorizam a continuidade e a harmonia, no sentido de regularidade (DONDIS, 2007). Princípios esses que, segundo Gomes Filho (2009), são operados pela Lei da Gestalt e oferecem suporte a esse sistema visual de leitura.

Na semana seguinte, cada participante trouxe no mínimo 03 imagens de temas diversos, incluindo fotografias abstratas, de natureza e desenhos com padrões. Além da situação abordada, as fotos que compõem o conjunto seguiram a proposição de evidenciar um padrão de repetição quanto a pose, enquadramento, cor e tonalidade. As captações foram realizadas no laboratório de narrativas visuais da instituição em questão, o que permitiu a obtenção de um ambiente mais escuro, o uso do projetor e dos equipamentos fotográficos.

O projetor estava fixado ao teto e a 2,5 metros de distância da tela de projeção. Foi utlizada uma câmera digital Canon T5i ajustada no modo manual com $1 / 5$ segundo de velocidade do obturador, 5,6 de abertura do diafragma e ISO 100.

No total, foram captadas 180 fotografias, sendo que apenas algumas delas foram escolhidas para análise e reforço dos pontos que visam obter diferentes resultados com a reprodução da técnica.

As imagens foram projetadas uma a uma e cada modelo interagiu com uma pose sobre a imagem projetada, imitando ações ou apenas utilizando da pele como superfície receptora. $O$ modelo era posicionado frente a tela de projeção e após a escolha da pose, ficava imóvel até o fechamento do obsturador da câmera. No exemplo a seguir pode-se observar o efeito obtido de uma mandala projetada em um modelo usando roupa preta sobre o fundo branco (Figura 3). 


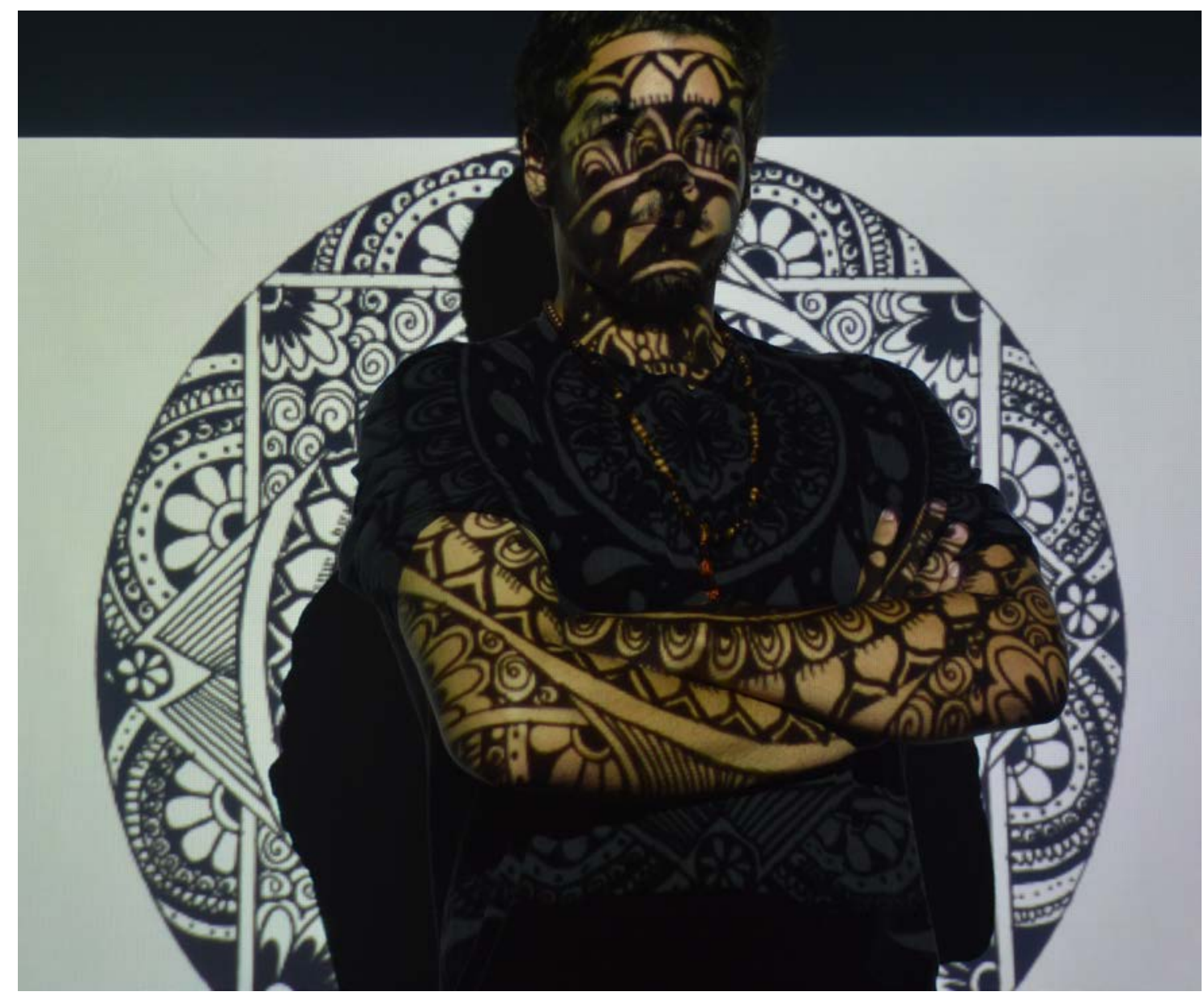

Figura 3 - Captação fotográfica utilizando a projeção com o tema mandala

Fonte: Captação e direção: Andre Luiz Pinto. Idealização, produção e modelo: Mikhael Luitgy de Araujo Gusso

Nesse caso, a roupa preta absorveu parte da imagem e realçou as projeções na pele dos braços e rosto, caracterizando a aplicação de uma tatuagem. A maior proximidade do modelo com a tela de projeção minimizou as áreas das sombras lateriais duras, reduzindo assim, as interferências indesejadas que pudessem comprometer a sensação de uniformidade do que estava sendo projetado. Desta forma, manteve-se a impressão de que o modelo, inserido por meio dessa intervenção fotográfica, pôde vivenciar aquele momento eternizado.

No próximo exemplo pode-se observar o efeito de uma imagem colorida com o fundo preto projetada em uma modelo usando roupa preta. As cores da projeção ficaram mais realçadas e o enquadramento mais fechado do ângulo de visão aproximou e ofereceu maior realismo a interação, maximizando assim, a área de captação. Já a posição centralizada, abandonou as regras de enquadramento (gold points) para incentivar uma ponte automática com o observador, induzindo-o à uma leitura de sua própria projeção e reconhecimento (Figura 4). 


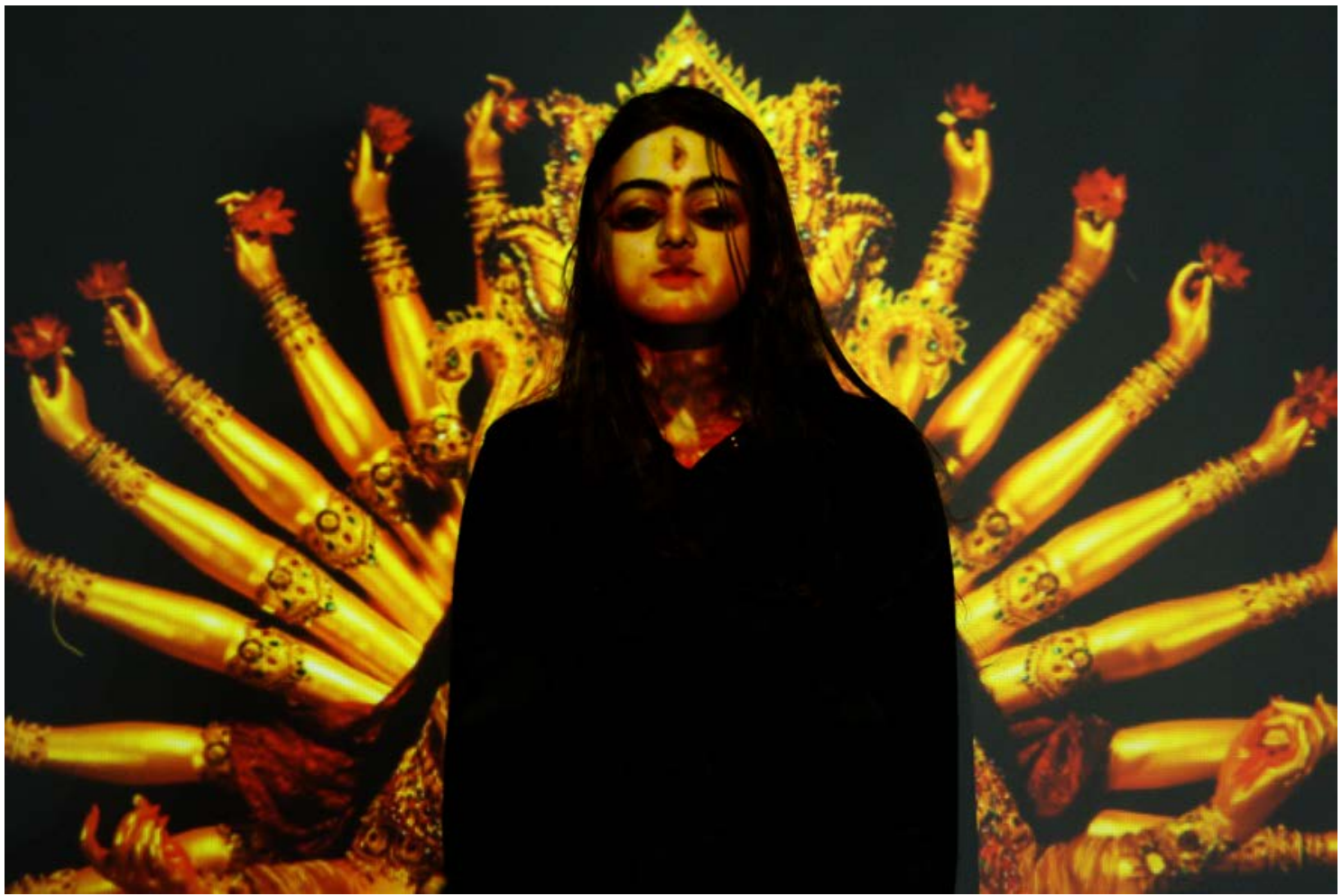

Figura 4 - Captação fotográfica utilizando a projeção com o tema deuses na Índia

Fonte: Captação e direção: Manuella de Godoy e Silva. Idealização, produção e modelo: Mariana de Souza Godoy

$\mathrm{Na}$ figura 5, a modelo usou uma roupa lisa branca e interagiu com um imagem de fundo claro. A posição lateral, a roupa clara e a maior proximidade da modelo com a tela de projeção foram os fatores que amenizaram as sombras duras, conduzindo a uma imagem de maior interação e menor distorção visual.

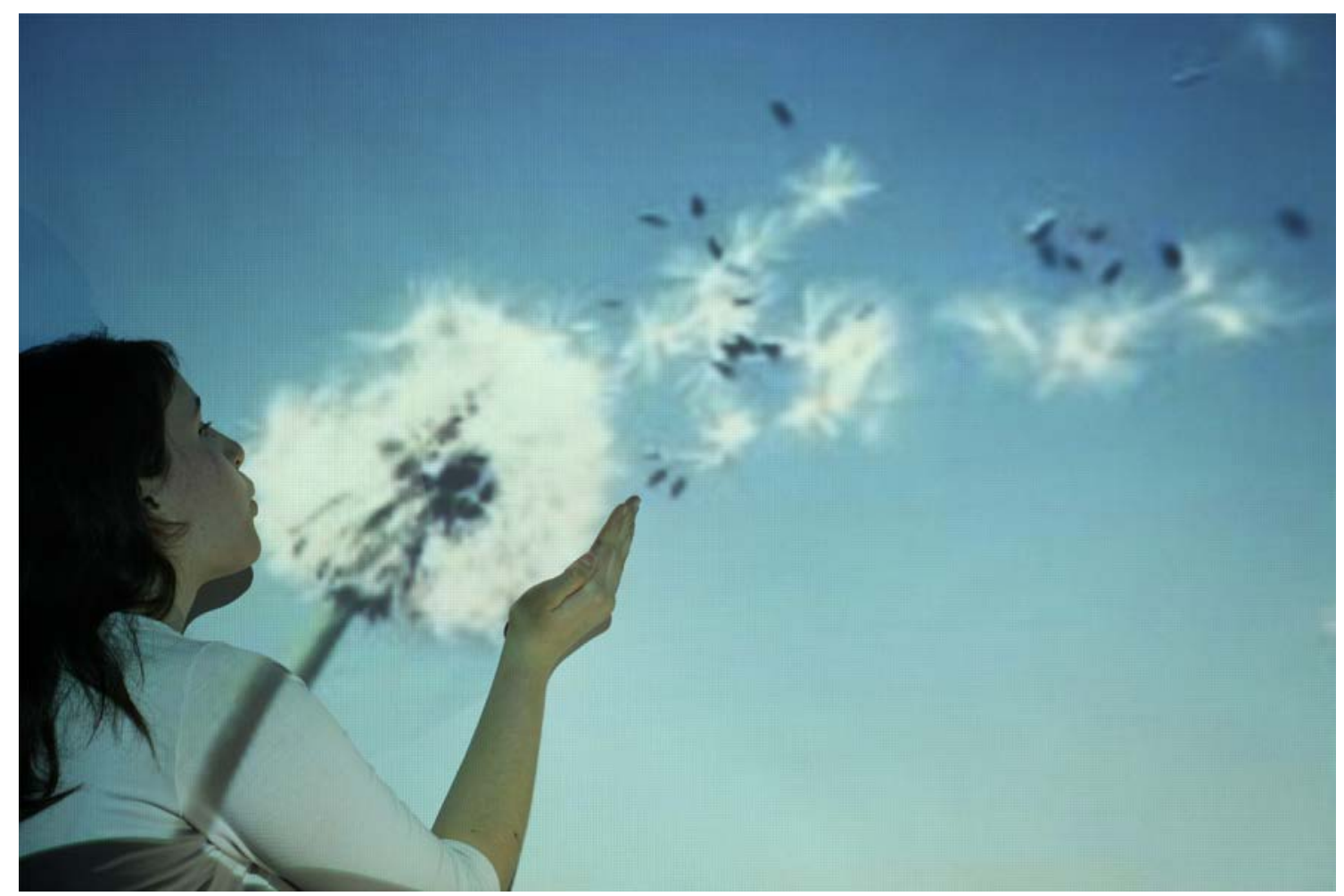


Figura 5 - Captação fotográfica utilizando a projeção com o tema natureza

Fonte: Captação e direção: Giovanni Akira Ukoni. Idealização, produção e modelo: Alana Cristina Cavichiolo

Com relação a técnica, pode-se observar na figura 6 que a modelo, com exceção dos olhos, está totalmente envolvida em um tecido liso branco. Nesse caso, a cor branca do figurino permitiu uma reprodução sem muitas distorções e variações de tonalidades. Visto que, o destaque da interferência criada pela modelo foi discreto e foi obtido mais pelo volume da mesma do que pela cor.

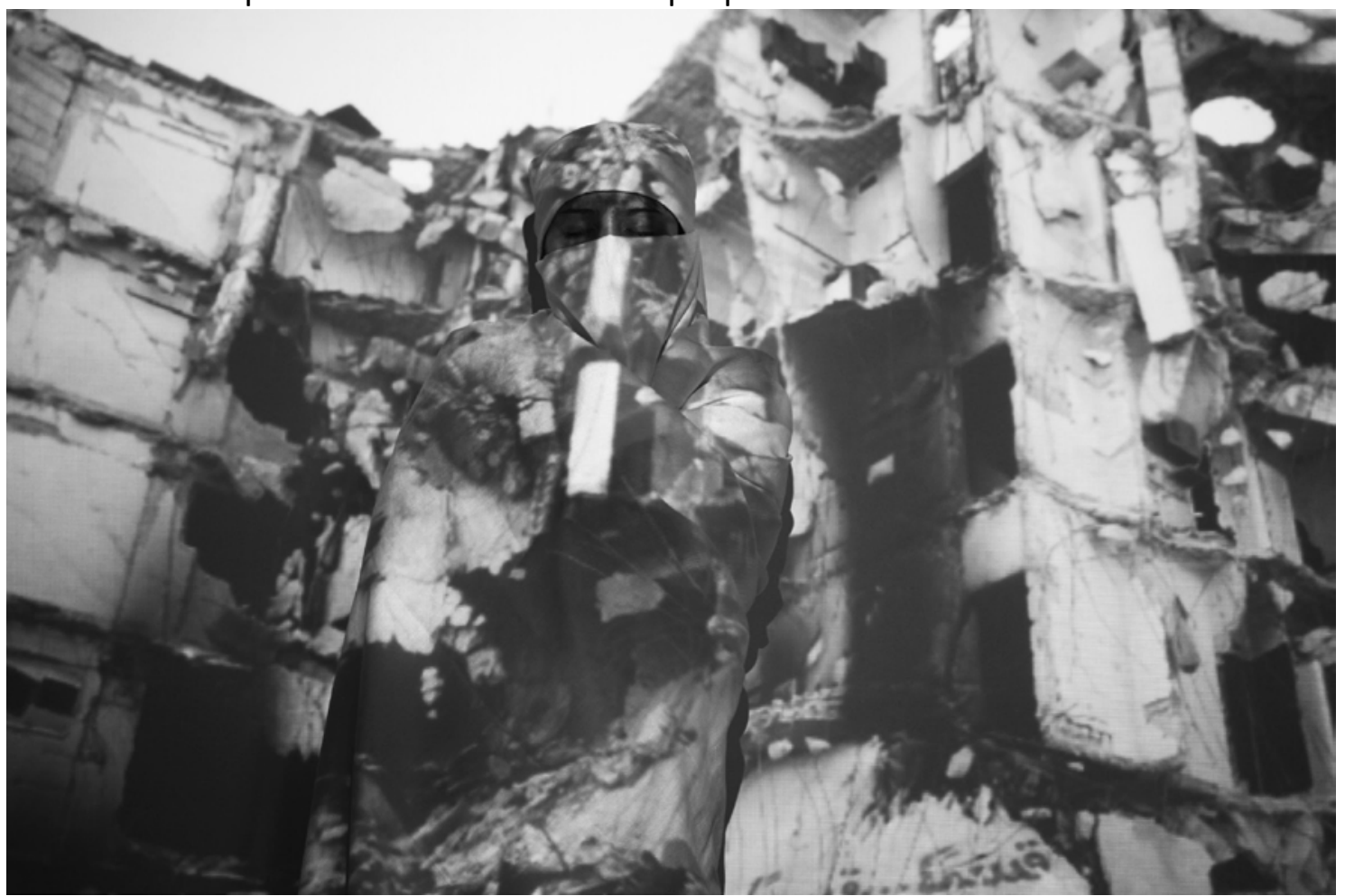

Figura 6 - Captação fotográfica utilizando a projeção com o tema ruínas da Síria

Fonte: Captação e direção: Silmara Takazaki e Gustavo Felipe Oliveira. Idealização, produção e modelo: Elisangela Lobo Schirigatti.

Ainda sobre a figura 6 , a vestimenta, em conjunto com os olhos fechados, remetem a sensação de morte ou inércia, exprimindo crueldade ao contexto. Por outro lado, esse fechamento, quando não explicado pela morte em si, mostra-se não sendo obtido de maneira proposital, tal como ocorre com a vedação dos olhos quando os mesmos são cerrados por uma banda ou faixa. Por isso, pode ser interpretado como uma demonstração da indiferença do próprio observador com relação aos acontecimentos expostos na película. Gerando assim, um clima de frialdade por parte do leitor.

\section{CONCLUSÃO}

A proposição de projetos de extensão que incluem a experimentação de novas técnicas são importantes para a absorção do conhecimento docente e influenciam na decisão de implementação de novos desafios no meio acadêmico. Nesse caso, o contato dos docentes com a técnica de captação fotográfica utilizando projeções que ocorreu a partir das atividades desenvolvidas no atelier de fotografia foi um mecanismo propulsor que contribuiu para a adoção da técnica nas aulas de fotografia. 
A técnica em questão, estimula na área de fotografia a prática de exercícios de enquadramento, estudo de contraste e sobreposição de imagens na pré-produção. Um fator inovador na era digital, pois os alunos de design estão acostumados a realizar a sobreposição na pós-produção, utilizando softwares de edição de imagens. Outros fatores desafiadores observados foram as configurações da câmera para a captação do movimento estático em condições adversas de iluminação.

As duas principais limitações encontradas na aplicação da técnica estavam realcionadas com o projetor. A primeira delas era o fato do projetor estar fixo no teto o que impediu maiores variações do tamanho da imagem projetada. A segunda adversidade estava associada a qualidade da luz do equipamento que também interferiu diretamente nos resultados, tornando as imagens captadas mais esmaecidas e de baixo contraste.

Em resumo, os resultados mostraram a importância entre a qualidade da luz do projetor com a qualidade da imagem projetada; das questões de nitidez com o uso do tripé e a pose estática do modelo; das cores da vestimenta da modelo com as cores da imagem projetada; do enquadramento obtido com a posição do projetor; e da volumetria do objeto fotografado com a atenuação das sombras.

Apesar dos discentes buscarem imagens com padrão visual, colorida ou preto e branca, o estudo utilizou imagens de autoria aleatória encontradas na internet. Contudo, recomenda-se em trabalhos futuros a utilização de composições resultantes de outras disciplinas do Curso de Design Gráfico, tais como ilustração, audiovisual e animação. Promovendo assim, por meio dessa prática, a interdisciplinariedade e uma maior interação entre autor e obra, o que pode gerar um processo com maior comprometimento e, consequentemente, resultados mais interessantes.

\section{REFERÊNCIAS}

CRAWLEY, Mike. Body Projection. Disponível na internet por http em: <http://br.blurb.com/books/3146469-body-projection>. Acesso em 17 dez. 2014

LAUPER, Cindy. I Drove All Night. In:Twelve Deadly Cyns...and Then. Sony BMG Music Entertainment, C1989. 1 DVD-ROM.

CLANG, John. Family matters. Disponível na internet por http em:

<http://www.johnclang.com/exhibition/strozzina.html>. Acesso em 17 dez. 2014

AYER, David. Time travel. Disponível na internet por http em:

<http://www.davisayer.com/>. Acesso em 17 dez. 2014

MASSARELLA, A. S. Finding the right words. Disponível na internet por http em: <https://www.flickr.com/photos/ashleysophiamassarella/5136109597/in/photostrea m/>. Acesso em 17 dez. 2014

GOLDSTEIN, Mark. A beginners guide to projection art photography. Disponível na internet por http em:

$<$ http://www.photographyblog.com/articles/a_beginners_guide_to_projection_art_ph otography/>. Acesso em 17 dez. 2014

ESHCHAR, Tom. No face. Disponível na internet por http em:

<http://www.tomasoart.com/noface>. Acesso em 17 dez. 2014 
FITZGERALD, Hannah. Projection Photography. Disponível na internet por http em: $<$ https://www.flickr.com/photos/hfphotography/sets/72157605774852254/>. Acesso em 17 dez. 2014

IDIGITALPHOTO. Projection. Disponível na internet por http em: <http://www.idigitalphoto.com/dictionary/projection>. Acesso em 17 dez. 2014

EPSON. Calculadora de distância de projeção. Disponível na internet por http em: $<$ http://global.latin.epson.com/br/Sala-De-Prensa/Generales/DistanciaCalculadora/539>. Acesso em 25 mar. 2015 (b)

EPSON. Guia de projetos: Como comprar um projetor novo. Disponível na internet por http em: <http://global.latin.epson.com/br/guiaproyectores>. Acesso em 25 mar. 2015 (a)

INTERNATIONAL COMMITEE FOR DISPLAY METROLOGY. IDMS version 1.03: 2012. Disponível na internet por http em: <http://www.icdmsid.org/downloads/idms1.html>. Acesso em 25 mar. 2015

DYPHOTOGRAPHY. Tom Eshchar shoots nude projections on naked bodies (NSFW). Disponível na internet por http em: <http://www.diyphotography.net/tom-eshcharshoots-nude-projections-on-naked-bodies/>. Acesso em 25 mar. 2015

THE COLOR LIGHT OUTPUT. Projector Buyer's Guide to Color Brightness by Model. Disponível na internet por http em:

$<$ http://www.colorlightoutput.com/Color_Brightness_Buyers_Guide.pdf $>$. Acesso em 25 mar. 2015

GOMES FILHO, João. Gestalt do objeto: sistema de leitura visual da forma. 9. e. São Paulo: Escrituras Editora, 2009.

DONDIS, Donis. Sintaxe da linguagem visual. 3. e. São Paulo: Martins Fontes, 2007.

COLOR LIGHT OUTPUT. What is color Light output. Disponível na internet por http em: <http://www.colorlightoutput.com/what-is-color-light-output.php>. Acesso em 25 mar. 2015

VAN SCHOOR, Friedrich; MAWAD, Tarek. Bioluminescent Forest. Disponível na internet por http em: <http://projection-mapping.org/bioluminescent-forest/>. Acesso em 25 mar. 2015

MUELLER, Eva. Projections. Disponível na internet por http em:

<https://www.pinterest.com/pin/451134087649595181/>. Acesso em 02 maio 2016 